\title{
Actualización en el diagnóstico y manejo de aspergilosis invasora en pacientes adultos
}

\author{
Ricardo Rabagliati
}

\section{Update in the diagnostic and therapeutic approach of invasive aspergillosis in adult population}

The invasive fungal disease produced by Aspergillus spp., is the infection by filamentous fungi most frequently reported among immunocompromised individuals and responsible for a very high mortality in this group of patients. In recent years, important advances have been made both from the diagnostic and therapeutic point of view. At present, a series of risk factors associated with its development have been identified, allowing the categorization of patients in high, intermediate and low risk of invasive aspergillosis (IA); and diagnostic criteria have also been established that consider factors of the host, traditional mycological laboratory, biomarkers such as galactomannan and $1 \rightarrow 3-\beta$-d-glucan, together with the better understanding and interpretation of the tomographic images that have allowed to reach a consensus on the diagnostic categories. This added to the incorporation of new antifungals and therapeutic strategies in different scenarios, have allowed decreasing the associated mortality. In this review, are updated the epidemiological aspects, the risk factors, the diagnosis, prevention and prophylaxis as well as the therapeutic confrontation, including strategies for the use of empirical, precocious and directed antifungal therapy, as well as the most relevant aspects of the first-choice and alternative antifungals for the IA management.

Keywords: Invasive aspergillosis; galactomannan; antifungal therapy; immunocompromised patients.

Palabras clave: Aspergilosis invasora; galactomanano; terapia antifúngica; pacientes inmunocomprometidos.

\section{Introducción}

\section{$\mathrm{L}$} a aspergilosis invasora (AI) es una enfermedad grave que afecta principalmente a pacientes inmunocomprometidos, provocando mortalidad elevada, descrita hasta $90 \%$, dependiendo del órgano afectado, estatus de inmunidad del paciente, momento del diagnóstico y la terapia antifúngica utilizada ${ }^{1-3}$. Si bien existen más de 200 especies de Aspergillus, la mayor parte de las infecciones son producidas por $A$. fumigatus, $A$. flavus, $A$. terreus y $A$. niger. La frecuencia de una especie sobre otra depende de distintos factores pudiendo variar en diferentes centros hospitalarios, aunque $A$. fumigatus es el más frecuentemente identificado ${ }^{3}$.

Este artículo de revisión entrega una puesta al día de AI en aspectos de epidemiología, factores de riesgo, elementos clínicos, diagnóstico, enfrentamiento terapéutico, prevención y desafíos futuros, basada en la revisión de la literatura científica más relevante, dirigida a médicos especialistas y no especialistas de nuestra región, que tratan a pacientes con AI, a fin de entregar una visión global complementaria a extensas guías clínicas publicadas en años recientes de la Asociación Americana de Enfermedades Infecciosas -IDSA- publicada el año 2016 de la Conferencia Europea de Infecciones en Leucemia -ECIL- del $2017^{5}$ y la guía conjunta de la Sociedad
Europea de Microbiología Clínica y Enfermedades Infecciosas, Conferederación Europea de Micología Médica y Sociedad Europea Respiratoria -ESCMID-ECMM-ERSpublicada este año ${ }^{6}$.

\section{Epidemiología}

Aspergilosis invasora se presenta en pacientes inmunocomprometidos por distintas causas: cánceres hematológicos, receptores de trasplante de precursores hematopoyéticos (TPH), trasplante de órganos sólidos (TOS), pacientes que reciben corticosteroides por período prolongados, pacientes con infección por VIH en etapas avanzadas, usuarios de fármacos inmunosupresores o agentes biológicos ${ }^{1-3,7-32}$; sin embargo, se debe señalar que durante los últimos años también se ha descrito con frecuencia creciente AI en algunos grupos de pacientes críticamente enfermos pero aparentemente inmunocompetentes ${ }^{8}$.

La frecuencia no es igual en cada uno de estos grupos (Tabla 1). La mayor incidencia se presenta en los pacientes con cáncer hematológico ${ }^{9,10}$; entre ellos, afecta con mayor frecuencia a pacientes con leucemia mieloide aguda (LMA) que con otras leucemias agudas o crónicas y, con menor frecuencia, linfoma y mieloma múltiple (MM). La
'Departamento de Enfermedades Infecciosas del Adulto. Facultad de Medicina. Pontificia Universidad Católica de Chile. Santiago, Chile.

Declaro no tener conflictos de interés en este tema. El presente estudio no tuvo financiamiento directo.

Recibido: 22 de enero de 2018 Aceptado: 25 de julio de 2018

Correspondencia a: Dr. Ricardo Rabagliati Borie rabagli@med.puc.cl 
Tabla 1. Frecuencias reportadas de aspergilosis invasora en distintos grupos de pacientes inmunocomprometidos y aparentemente inmunocompetentes

Diagnóstico de base agrupados
patológica
Pacientes hemato-oncológicos
- Aplasia medular
- Leucemia mieloide aguda
- Leucemia linfática aguda
- Otros cánceres hematológicos
- Mieloma múltiple

Incidencia reportada

\section{Referencia}

$9,8-11,5 \%$

22,23

$7,1-10,5 \%$

$4,3 \%$

$0,35-2,4 \%$

$0,2 \%$

9,15

15

15

14

Pacientes receptores de trasplante de precursores hematopoyéticos

- Alogeneico 6,3-12\%

- Autólogo

$0,3-5,3 \%$

$16,18,20$

$16,18,20$

Pacientes receptores de trasplante de órganos sólidos

- Trasplante pulmonar

- Trasplante cardiaco

- Trasplante intestinal

- Trasplante hepático

- Trasplante de páncreas

- Trasplante renal

$6 \%$

$5,2 \%$

$2,2 \%$

$2 \%$

$1,1-2,9 \%$

$0,7 \%$

Pacientes aparentemente inmunocompetentes

- Pacientes críticos con EPOC

- Pacientes críticos

\section{$0,36 \%$}

$0,2 \%$

$0,02-0,6 \%$

$0,01 \%$

- Pacientes con infección por VIH

- Pacientes receptores de anti-FNT

$E P O C=$ enfermedad pulmonar obstructiva crónica. FNT=Factor de necrosis tumoral (ej.: inflixi$\mathrm{mab})$. receptores de $\mathrm{TPH}^{7,15-21}$; se debe distinguir una mayor incidencia en los receptores de trasplante alogeneico respecto los autólogos (10 vs 2,6\%) ${ }^{16}$. En ellos, si bien la AI puede presentarse durante la fase neutropénica pre implantación, también puede manifestarse durante la siguiente fase de inmunodepresión celular, período de enfermedad de injerto versus hospedero agravado por el uso de inmunosupresores propio del manejo de esta complicación y durante la reactivación de citomegalovirus ${ }^{17}$. Otra condición hematológica en que también se presenta, aunque existen menos datos publicados es en aplasia medular en que se reporta que Aspergillus spp es el agente responsable de la mayor parte de las $\mathrm{EFI}^{22,23}$.

En cuanto a receptores de TOS, la incidencia es diferente según el órgano trasplantado ${ }^{24}$; en orden decreciente, el grupo más afectado corresponde a pacientes receptores de trasplante pulmonar, luego cardiaco, después hígado y muy poco frecuente en receptores de trasplante renal ${ }^{16,24}$.

En cambio, en pacientes inmunocomprometidos por uso de corticosteroides o inmunosupresores por enfermedad autoinmune está menos descrito ${ }^{25}$. En los pacientes con infección por VIH avanzada no es frecuente ${ }^{26,27}$, menos en la actualidad, en consideración a la recuperación inmune con terapia anti-retroviral. Otro grupo en quienes se han reportado casos de AI es el de aquellos pacientes que reciben agentes biológicos monoclonales como los antagonistas de factor de necrosis tumoral (FNT- $\alpha$ ) como infliximab, adalimumab, etanercept ${ }^{28}$. Como se señalaba previamente, un grupo emergente reportado en el último tiempo, es el de pacientes graves hospitalizados en unidades de paciente crítico (UPC), aparentemente inmuncompetentes, especialmente aquellos con enfermedad pulmonar obstructiva crónica (EPOC), cirrosis hepática y post influenza ${ }^{8,29-31}$.

De acuerdo a las frecuencias reportadas por patología de base, se pueden categorizar los pacientes en alto, mediano y bajo riesgo para adquirir una AI (Tabla 2), lo que permite plantear estrategias diferenciadas de profilaxis, enfrentamiento diagnóstico y opciones terapéuticas frente al caso individual ${ }^{32}$.

\section{Factores de riesgo}

En la Tabla 3 se presentan los factores de riesgo más frecuentes. Indudablemente, el más relevante es la neutropenia; mientras más profunda y prolongada sea, mayor será el riesgo de adquisición de una AI. Entre los otros factores descritos se debe mencionar la inmunosupresión asociada a medicamentos, la condición biológica y la infección por citomegalovirus por su rol inmunomodulador $^{7,16-19,33}$. Otro factor que se debe destacar es la exposición medioambiental; existen numerosos reportes que asocian construcciones en hospitales con brotes de $\mathrm{AI}$ en pacientes profundamente inmunocomprometidos ${ }^{34}$. 


\begin{tabular}{|c|c|c|}
\hline Riesgo bajo incidencia de $\mathrm{Al}<2 \%$ & Riesgo intermedio incidencia Al 2-5\% & Alto riesgo incidencia $\mathrm{Al}>5 \%$ \\
\hline TPH autólogo & Leucemia linfática aguda & Leucemia mieloide aguda \\
\hline Enfermedad de Hodgkin & Linfoma no Hodgkin & TPH alogénico \\
\hline Síndromes linfoproliferativo crónicos & Leucemia linfática crónica & Trasplante pulmonar \\
\hline Cánceres de órganos sólidos & Síndrome mielodisplástico & Aplasia medular \\
\hline Lupus eritematoso sistémico & Trasplante cardíaco & \\
\hline $\mathrm{VIH} / \mathrm{SIDA}$ & Trasplante hepático & \\
\hline \multicolumn{3}{|l|}{ Trasplante renal } \\
\hline \multicolumn{3}{|l|}{ EPOC } \\
\hline Paciente crítico en UCl & & \\
\hline
\end{tabular}

Esta situación ocurre por el significativo incremento de dispersión de conidias de Aspergillus spp. a través del aire que, debido a su pequeño tamaño, 2 a $3 \mu$, tienen capacidad de llegar por vía área hasta los alveolos pulmonares de los pacientes susceptibles ${ }^{1,2}$.

Recientemente se han descrito factores genéticos que confieren mayor susceptibilidad del hospedero a contraer AI, tales como polimorfismos en genes de la inmunidad innata, expresión de receptores como toll like receptors (TLR), de citoquinas y de sus receptores ${ }^{35}$.

\section{Manifestaciones clínicas}

La aspergilosis invasora puede afectar a cualquier órgano; sin embargo, como el mecanismo más frecuente de adquisición de la infección es inhalatorio, lo más frecuente es el compromiso pulmonar seguido del rinosinusal. Menos usual es el compromiso cerebral e infrecuentes son la enfermedad gastrointestinal, cutánea, cardíaca, ocular y osteo-articular ${ }^{3}$. En general, la vía cutánea está asociada a uso de catéteres o contacto prolongado con material adhesivo o quemaduras. Las otras localizaciones mencionadas pueden presentarse en el contexto de una infección diseminada por vía hematógena, exposición ambiental o durante procedimientos por contaminación de insumos o dispositivos ${ }^{36-38}$.

El síntoma más frecuente es la fiebre elevada, aunque se debe reconocer que no siempre está presente. Los síntomas de localización se manifiestan en la medida que el compromiso orgánico progresa, es decir, en caso de aspergilosis pulmonar invasora (API) los pacientes presentan tos, puntada de costado, expectoración hemoptoica en diverso grado hasta hemoptisis ${ }^{37}$. En el caso de sinusitis se puede presentar dolor facial, cefalea, aumento
Tabla 3. Factores de riesgo de aspergilosis invasora

Neutropenia

Enfermedad de injerto sobre hospedero y terapia inmunosupresora asociada

Trasplante de precursores hematopoyéticos alogénico

Trasplante de órganos sólidos (pulmón, corazón, hígado)

Linfocitopenia CD4+< 100 céls/mm³

Exposición medioambiental

Colonización previa por Aspergillus spp.

Infección por citomegalovirus

Uso de terapias biológicas como anti-TNF $\alpha$ y anti-CD52

Falla renal en hemodiálisis

Cirrosis hepática

de volumen maxilar, rinorrea serosa y epistaxis. Tanto en éstas como en otras localizaciones, dado sus manifestaciones inespecíficas, el diagnóstico requiere un alto grado de sospecha ${ }^{38-40}$.

\section{Diagnóstico}

Suele ser un desafío debido a las múltiples dificultades para demostrar la presencia de Aspergillus spp. en una muestra clínica representativa del sitio afectado.

En la actualidad, los criterios diagnósticos formulados por la EORTC/MSG ${ }^{41,42}$ son ampliamente utilizados. Considera factores del hospedero, microbiológicos e histológicos para concluir que se trata de una infección posible, probable o probada (Tabla 4). Si bien estos criterios se postularon originalmente para uniformar la denominación 
de la certeza de infección en la publicación de estudios de AI, en la actualidad la mayoría de los grupos se encuentran familiarizados con su uso; sin embargo, se debe tener en cuenta que para las decisiones terapéuticas, junto a los criterios diagnósticos debe tenerse siempre presente el juicio clínico frente al cuadro del paciente.

\section{Estudio de laboratorio}

Las muestras obtenidas deben someterse a los procedimientos convencionales que incluye tinción de $\mathrm{KOH}$ y blanco de calco-flúor junto al cultivo de hongos ${ }^{43}$, además del estudio anatomo-patológico para confirmar la invasión fúngica. El aspecto clásico del laboratorio es la observación de hifas hialinas, angostas (3 a 6 micras), septadas, con ramificaciones dicotómicas en $45^{\circ 43}$. Los hemocultivos suelen ser negativos, incluso en los casos de infección diseminada; su positividad debe hacer pensar en infecciones intravasculares o contaminación de la muestra.

\section{Marcadores solubles}

El estudio con bio-marcadores se ha posicionado como una importante opción no invasora de apoyo diagnóstico y está incluido en los criterios EORTC/MSG ${ }^{41,42}$. La mayor experiencia publicada es con galactomanano (GM) y en segundo lugar con $1,3 \rightarrow \beta$-d-glucano (BDG).

El galactomanano es un componente de la pared fúngica; en la medida que crecen las hifas se va liberando y da la posibilidad de medirlo en sangre, apoyando el diagnóstico de infección invasora por Aspergillus spp.,

Tabla 4. Criterios diagnósticos de aspergilosis invasora seleccionados de criterios de enfermedad fúngica invasora según EORTC/MSG ${ }^{41,42}$

Factores del hospedero Neutropenia

Receptor de TPH

Corticosteroides por más de tres semanas

Uso de inmunosupresores

Inmunodeficiencia primaria

Criterios clínicos

Compromiso imagenológico pulmonar (al menos uno):

- Nódulos con o sin halo, creciente aéreo o cavidad

- Traqueobronquitis

- Rinosinusitis

- Infección de sistema nervioso central

Criterios micológicos Directos: tinciones o cultivos positivos Indirectos: Galactomamano y $\beta$-D-glucano

Definición de infección

Posible

Probable

Factores del hospedero + criterios clínicos

Probada
Factores del hospedero + criterios clínicos + micológicos

Aspergillus en cultivos de cavidad estéril o sangre o estudio histológico que demuestre invasión fúngica aunque también puede resultar positivo en infecciones por Fusarium spp. y muy raramente en otras EFI como histoplasmosis, blastomicosis y peniciliosis. No está estandarizado su uso aún en otras muestras clínicas como LCR, líquido pleural, u otros ${ }^{44,45}$. Sin embargo, existe experiencia reportada por Chong y cols., quien determinó GM en LCR de pacientes con compromiso cerebral por Aspergillus spp. obteniendo sensibilidad de $88,2 \%$, especificidad de $96,3 \%$ ya fuese con punto de corte de 0,5 o de 1 o de $2^{46}$. El resultado de GM se expresa como un índice de densidad óptica; un valor en suero $\geq 0,5$ se considera positivo con sensibilidad hasta $97,4 \%$ y especificidad de $90,5 \%$ en pacientes neutropénicos y receptores de TPH alogénico ${ }^{45,47-49}$. En otros grupos de pacientes como receptores de TOS u otras condiciones, la sensibilidad disminuye $e^{50,51}$ lo que parece estar en relación a la diferente capacidad de angio-invasión fúngica que se produce en estos pacientes respecto a los hematológicos. En relación al uso de GM en LBA la mayoría de los autores coincide que se debe considerar positivo un valor $\geq 1$, con sensibilidad de $91,3 \%$ y valor predictor positivo y negativo de 76 y $96 \%$, respectivamente ${ }^{52}$; si valores inferiores puedan catalogarse de positivos a favor de infección invasora es materia de discusión.

\section{$1,3 \rightarrow \beta$-d-glucano}

Puede resultar positivo en casos de infección por Candida, Aspergillus, Fusarium, Pneumocystis entre otros, por lo que no es específico y presenta frecuentemente falsos positivos por lo que su interpretación debe ser cautelosa ${ }^{44}$. También puede medirse en LBA; sin embargo, se dispone de menos experiencia al respecto.

Existen otros marcadores, como antígeno de manano/ antimanano y "lateral flow device" cuya utilidad está por definirse ${ }^{53}$. En nuestra experiencia, este último tiene un menor rendimiento que GM (Nota del Editor: ver artículo en pág. 574 y por último, la prueba de reacción de polimerasa en cadena (RPC) ha sido reconocida en publicaciones recientes como un importante avance en el diagnóstico ${ }^{54}$ incluyendo el efecto diagnóstico sumatorio al asociarlo a GM en suero y/o LBA ${ }^{55}$.

\section{Imagenología}

Otro de los pilares claves en el diagnóstico es la adecuada interpretación de las imágenes, en particular el uso de tomografía computarizada para AI en pacientes neutropénicos. La imagen de nódulos rodeados de halo (Figura 1) que representan la hemorragia secundaria a la angioinvasión característica del hongo sugiere fuertemente el diagnóstico en un paciente con factores de riesgo ${ }^{56}$. En pacientes neutropénicos se ha descrito que las imágenes nodulares aumentan de tamaño, hasta cuatro veces durante los primeros siete días de evolución, transformándose en imágenes cavitadas, descritas como creciente aéreo, 
entre el día 7 y 14 de evolución ${ }^{56}$. Es necesario considerar leucemia aguda, asociado a construcciones, bajando de que los nódulos no son patognomónicos de $\mathrm{AI}$; de hecho, 50 a 43\% su incidencia con uso de profilaxis antifúngica otras infecciones fúngicas, bacterianas o cuadros no in- y luego a $0 \%$ al incorporar filtros HEPA ${ }^{63}$.

fecciosos pueden manifestarse de manera similar ${ }^{57}$. Más Sin duda, junto a los AP se debe contar con medidas recientemente se ha reconocido que existen imágenes que complementarias que eviten la potencial exposición de son más precoces que el nódulo con halo y representan el pacientes a aire con presencia de conidias de Aspergillus compromiso pulmonar temprano, permitiendo identificar spp. y otros hongos patógenos, entre las cuales destacan una fase bronquial de AI que puede visualizarse como las políticas que eviten la exposición a polvo ambiental bronquiectasias, árbol en brote o vidrio esmerilado ${ }^{58}$. En a pacientes derivado de construcciones, remodelaciones pacientes no-neutropénicos, no se deben esperar la clásica o mantenciones de la infraestructura ${ }^{64-66}$.

imagen de nódulo con signo de halo; de hecho, en un estudio de Taccone y cols., en pacientes críticos o con EPOC, sólo $30 \%$ de los casos tenían imágenes tomográficas Tratamiento antifúngico

clásicas de $\mathrm{AI}^{8}$. En pacientes neutropénicos se ha sugerido la utilidad de complementar las imágenes con contrate en fase venosa para poder visualizar el componente de infarto pulmonar en el nódulo, lo que permite diferenciar de consolidaciones nodulares de otras etiologías ${ }^{59}$. Otro aporte de las imágenes es el uso de la tomografía con emisión de positrones (Positron Emission TomographyComputed Tomography-PET-CT por sus siglas en inglés), con particular utilidad en la determinación de actividad inflamatoria en el foco de AI, que podría ser de utilidad como información adicional para definir plazos de terapia en casos individuales ${ }^{60}$.

\section{Prevención de la exposición}

En consideración que la vía más frecuente de exposición a Aspergillus es la vía aérea, los intentos por disminuir la exposición (o carga fúngica), especialmente durante los períodos de mayor susceptibilidad, han llevado a diseñar infraestructura específica más segura para los pacientes en mayor riesgo de desarrollar esta complicación. De hecho, hoy en día es posible reducir la exposición con el adecuado manejo del aire durante la estadía en hospitales, en habitaciones especialmente diseñadas e identificadas con el nombre de ambiente protegido (AP), entendido como una pieza de uso individual, con presión positiva al interior respecto a pasillos y exterior, con al menos 12 recambios de aire por hora que ingresa filtrado por unidades de alta eficiencia (High Efficiency Particulate Air-HEPA por sus siglas en inglés) (Figura 2).

Las mediciones de carga fúngica en aire ambiental publicada en la década de los 80 por Rhame y cols. y Sherertz y cols., incluyendo período pre y post incorporación de filtros HEPA, permitieron demostrar el beneficio de su uso, con reducciones significativas de las cargas fúngicas en aire ambiental de 2 a 0,8 y de 0,4 a $0,001 \mathrm{ufc} / \mathrm{m}^{3}$ con concomitante disminución de las incidencia de AI de 15 a $8 \%$ y 33 a $0 \%$, respectivamente ${ }^{61,62}$. De manera similar Oren y cols., publicaron su experiencia al lograr intervenir favorablemente en un brote de AI, en pacientes con

En esta sección se presentan los antifúngicos disponibles, las asociaciones de antifúngicos, las estrategias de enfrentamiento, las indicaciones quirúrgicas, el seguimiento con GM y la duración de la terapia.



Figura 1. TAC de tórax que muestra nódulo con halo en un paciente con neutropenia profunda y fiebre, altamente sugerente de aspergilosis invasora.

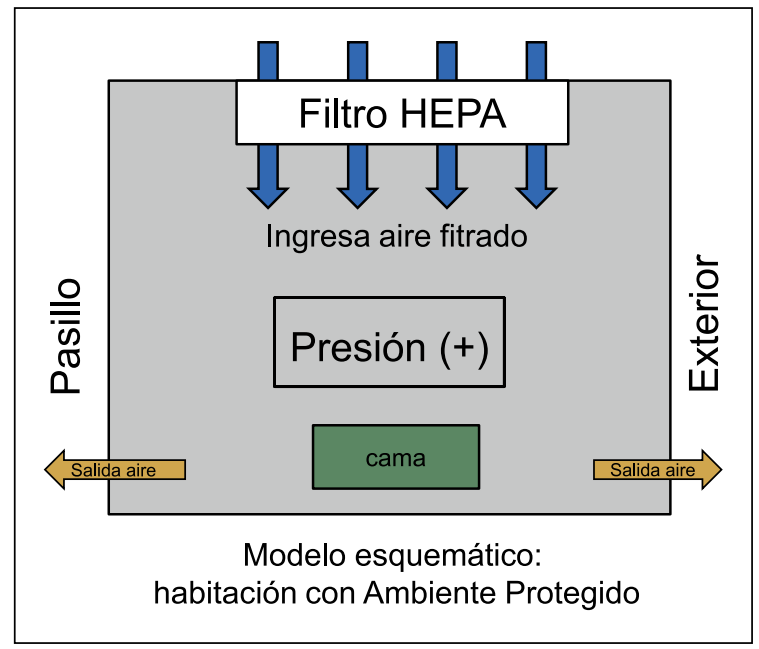

Figura 2. Diagrama esquemático de ambiente protegido: habitación individual, aire ingresa a través de filtro de alta eficiencia (HEPA), manteniendo presión positiva respecto al pasillo y al exterior y asegurando al menos 12 recambios de aire por hora. 


\section{Antifúngicos}

Por años, anfotericina fue la terapia de elección, aunque con pobres resultados y alta toxicidad en su formulación desoxicolato. En los últimos años se han producido notables avances en las opciones terapéuticas con los nuevos triazoles que han cambiado la historia de la enfermedad, las formulaciones lipídicas de anfotericina con relativa baja toxicidad y la nueva familia de equinocandinas que también han sido evaluadas como opciones terapéuticas de AI. A continuación, se describen los antifúngicos con actividad sobre Aspergillus spp. y en la Tabla 5 se resumen las dosis de cada uno de ellos.

\section{Triazoles}

Actúan sobre la síntesis de ergosterol inhibiendo la enzima lanosterol 14- $\alpha$-desmetilasa resultando en alteración de la membrana celular que lleva a la muerte del hongo ${ }^{67}$. Uno de los problemas comunes a este grupo son las interacciones farmacológicas, entre ellas con los inmunosupresores cuyas concentraciones plasmáticas aumentan y en caso de uso conjunto con alcaloides de la vinca existe alto riesgo de neurotoxicidad por lo que debe evitarse su uso concomitante ${ }^{4-6}$.

\section{Voriconazol}

Es el antifúngico de primera elección en AI, tanto en el compromiso pulmonar como extra-pulmonar de pacientes neutropénicos y no-neutropénicos ${ }^{4-6}$.

Su efectividad en AI, fue demostrada por Herbretch y cols., en un estudio randomizado, comparativo con anfotericina $\mathrm{B}$ desoxicolato, en que logró respuesta completa o parcial en $52,8 \%$ de los pacientes y significativa mayor sobrevida ${ }^{68}$. También se ha estudiado su rol como antifúngico profiláctico en $\mathrm{TPH}$, sin demostrar superioridad sobre fluconazol ${ }^{69}$.

Se encuentra disponible en comprimidos y en solución intravenosa con ciclodextrina. De preferencia, el inicio de la terapia debe ser intravenoso; en pacientes con insuficiencia renal con clearance de creatinina menor a $50 \mathrm{ml} /$ min se puede acumular la ciclodextrina por lo que se debe preferir la formulación oral. Los comprimidos tienen buena biodisponibilidad, ya sea en ayunas o con alimentos. Voriconazol tiene buena distribución en todos los tejidos; en el sistema nervioso central (SNC) su concentración es aproximadamente $50 \%$ de la concentración plasmática. Los principales efectos adversos son alteraciones visuales, alucinaciones, hepatotoxicidad y fotosensibilidad ${ }^{67}$. Se recomienda medir su concentración plasmática, a fin de asegurar concentración entre 1 y $5,5 \mu \mathrm{g} / \mathrm{ml}$, que se asocia a mejor respuesta y evita la toxicidad descrita con concentraciones mayores $^{70}$.

\section{Posaconazol}

Es una alternativa para pacientes en que no es posible utilizar voriconazol. Su mayor evidencia es en profilaxis en pacientes neutropénicos post quimioterapia de LMA o síndrome mielodisplástico evidenciando reducción de EFI, incluso disminución de $\mathrm{AI}^{71,72}$. En terapia, un estudio sobre pacientes intolerantes o refractarios a terapia convencional de AI logró respuesta satisfactoria con posaconazol en $42 \%$ de ellos ${ }^{73}$.

Se encuentra disponible en solución oral y en compri-

Tabla 5. Dosis y presentación de antifúngicos utilizados en tratamiento de aspergilosis invasora

\begin{tabular}{|c|c|c|c|c|}
\hline Antifúngico & Dosis & Vía & Presentación & Observaciones \\
\hline Voriconazol & $\begin{array}{l}\text { Carga } 6 \mathrm{mg} / \mathrm{kg} \text { cada } 12 \mathrm{~h} \text { día } 1 \\
\text { Mantención } 4 \mathrm{mg} / \mathrm{kg} \text { cada } 12 \mathrm{~h}\end{array}$ & $\begin{array}{l}\text { iv } \\
\text { vo }\end{array}$ & $\begin{array}{l}\text { Frasco amp } 200 \mathrm{mg} \\
\text { Comprimidos } 200 \mathrm{mg}\end{array}$ & $\begin{array}{l}\text { Tratamiento de elección. Evitar formulación iv en caso de clearance crea- } \\
\text { tinina }<50 \mathrm{ml} / \mathrm{min} \\
\text { Reducir dosis en } 50 \% \text { en insuficiencia hepática moderada } \\
\text { Controlar concentración plasmática } \\
\text { Contraindicado uso junto con sirolimus y rifampicina }\end{array}$ \\
\hline Posaconazol & $\begin{array}{l}\text { Profilaxis } 200 \mathrm{mg} \text { cada } 8 \mathrm{~h} \\
\text { Terapia } 200 \mathrm{mg} \text { cada } 6 \mathrm{~h}\end{array}$ & vo & $\begin{array}{l}\text { Solución oral } 200 \\
\mathrm{mg} / 5 \mathrm{ml}\end{array}$ & $\begin{array}{l}\text { Terapia alternativa } \\
\text { Evitar uso junto a efavirenz } \\
\text { Contraindicado uso junto con alcaloides de la vinka y sirolimus }\end{array}$ \\
\hline Itraconazol & 400 mg al día & vo & Comprimidos $100 \mathrm{mg}$ & $\begin{array}{l}\text { Terapia alternativa } \\
\text { Baja biodisponibilidad }\end{array}$ \\
\hline Anfotericina liposomal & $3-5 \mathrm{mg} / \mathrm{kg} / \mathrm{día}$ & iv & Frasco $50 \mathrm{mg}$ & Primera opción como terapia alternativa \\
\hline Anidulafungina & $\begin{array}{l}\text { Carga } 200 \mathrm{mg} \\
\text { Mantención } 100 \mathrm{mg}\end{array}$ & iv & Frasco $100 \mathrm{mg}$ & $\begin{array}{l}\text { Terapia alternativa } \\
\text { Datos de efectividad exclusivamente en su uso combinado con voriconazol }\end{array}$ \\
\hline Caspofungina & $\begin{array}{l}\text { Carga } 70 \mathrm{mg} \\
\text { Mantención } 50 \mathrm{mg}\end{array}$ & iv & Frasco $50 \mathrm{mg}$ & $\begin{array}{l}\text { Terapia alternativa } \\
\text { Subir dosis a } 70 \mathrm{mg} / \mathrm{d} \text { en caso de uso concomitante de carbamazepina, } \\
\text { fenitoina, dexametasona, efavirenz, nevirapina, rifampicina. Bajar dosis a } \\
35 \mathrm{mg} / \mathrm{d} \text { en insuficiencia hepática moderada }\end{array}$ \\
\hline Micafungina & $100-150 \mathrm{mg} / \mathrm{d}$ & iv & Frasco $50 \mathrm{mg}$ & Terapia alternativa \\
\hline
\end{tabular}


midos, aunque actualmente esta última no está presente en todos los países. Tiene absorción saturable por lo que la carga no es posible, sus concentraciones plasmáticas alcanzan su estado estable después de una semana. Efectos adversos, se describen similares a otros azoles pero $\sin$ las alteraciones visuales descritas para voriconazol ${ }^{67}$.

\section{Isavuconazol}

Se trata del triazol más reciente. Tiene actividad sobre Aspergillus spp. y otros hongos filamentosos. Los resultados del estudio multicéntrico, randomizado, doble ciego demostraron no inferioridad con voriconazol en tratamiento de infección por hongos filamentosos, incluido Aspergillus spp. ${ }^{74}$. Por el momento no se encuentra disponible en Latinoamérica. Para las guías ECIL y ESCMID-ECMM-ERS, tiene el mismo nivel de recomendación que voriconazol como primera opción para terapia de $\mathrm{AI}^{5,6}$.

\section{Itraconazol}

Es el azol con actividad anti filamentosos más antiguo; en la actualidad tiene un lugar menor en la terapia o profilaxis de AI. Uno de los mejores resultados publicados se obtuvo con uso secuencial intravenoso y luego oral durante 12 semanas obteniendo respuesta parcial y completa en $48 \%$ de los pacientes en una serie de 31 pacientes en un estudio no comparativo ${ }^{75}$.

Existe presentación en cápsulas, solución oral y formulación para uso intravenoso. En Chile sólo disponemos de cápsulas, que tienen baja biodisponibilidad. En general, no es bien tolerado por toxicidad gastrointestinal -náuseas y vómitos- que lleva frecuentemente a suspensión de tratamiento. Otros efectos adversos descritos son hepatitis $\mathrm{y}$, con menor frecuencia, inotropismo negativo, por lo que se debe ser muy cauto en su indicación en pacientes con disfunción ventricular. Su uso debería incluir la monitorización de sus concentraciones plasmáticas.

\section{Polienos}

Actúan por unión a ergosterol, el principal esterol de la membrana fúngica, generando la formación de canales iónicos que alteran la permeabilidad y llevan a la muerte del hongo. Existen como anfotericina desoxicolato y formulaciones lipídicas: liposomal, complejo lipídico y dispersión coloidal ${ }^{67}$. Son activas contra la mayoría de las especies de Aspergillus, con excepción de A. terreus que es naturalmente resistente a anfotericina.

Su mayor toxicidad es con la formulación desoxicolato que frecuentemente produce deterioro de la función renal por vasoconstricción de la arteriola glomerular aferente, altercaciones hidroelectrolíticas como hipokalemia e hipomagnesemia, además de fiebre y calofríos asociados a la infusión ${ }^{67}$. En cambio, con las formulaciones lipídicas el riesgo de toxicidad es significativamente menor, siendo especialmente bajo con la formulación liposomal com- parada con dispersión coloidal o complejo lipídico. Sin embargo, un aspecto relevante a considerar es el elevado costo de estas formulaciones lipídicas.

Al agrupar estudios retrospectivos, la mejor respuesta con anfotericina liposomal en infecciones por filamentosos es de $51 \%{ }^{76}$. Se ha explorado obtener mejores resultados en AI con dosis de $10 \mathrm{mg} / \mathrm{kg}$ de anfotericina liposomal; no obstante, no se ha logrado demostrar beneficio con dosificaciones superiores a la estándar de $3 \mathrm{mg} / \mathrm{kg}^{77}$. Considerando su efectividad y relativa baja toxicidad, en casos en que no sea posible usar voriconazol o como opción de salvataje, anfotericina liposomal es la primera alternativa; por el contrario, se debe evitar el uso de anfotericina desoxicolato en consideración de su alta toxicidad, en especial en aquellos pacientes con mayor riesgo de nefrotoxidad ${ }^{78}$. También se ha explorado profilaxis de AI con anfotericina liposomal nebulizada en receptores de trasplante pulmonar con resultados favorables ${ }^{79}$. Esta opción se encuentra dentro de las recomendaciones para profilaxis en trasplante pulmonar ${ }^{4}$ y puede considerarse como alternativa en pacientes hamatológicos ${ }^{6}$.

\section{Equinocandinas}

Son compuestos semisintéticos que actúan por inhibición no competitiva de la síntesis de 1,3- $\beta$-d-glucano, polisacárido de la pared fúngica que junto a la quitina le dan la forma y resistencia. Actualmente hay tres disponibles: anidulafungina, caspofungina y micafungina, solamente disponibles en formulación iv. Generalmente son bien toleradas, con baja frecuencia de efectos adversos; sólo en algunos pacientes se observa hepatotoxicidad ${ }^{67}$.

Existe mayor información con el uso de caspofungina en AI que con otras equinocandinas. En un estudio de pacientes hemato-oncológicos con $\mathrm{AI}$ que recibieron caspofungina como terapia primaria, la respuesta favorable fue de $33 \%{ }^{80}$; en cambio, en experiencia reportada en infección refractaria o en intolerantes se han publicado resultados favorables de $55,6 \%{ }^{81}$. Pueden presentarse interacciones con el uso de efavirenz, nelfinavir, nevirapina, fenitoina, rifampicina, dexametasona y carbamazepina, fármacos que reducen las concentraciones de caspofungina lo que obliga a subir la dosis del antifúngico.

Por otra parte, micafungina ha sido utilizada en profilaxis de EFI en TPH, demostrando superioridad vs fluconazol ${ }^{2}$. En un estudio multicéntrico de AI refractaria o intolerantes a terapia, micafungina logró tasas de respuesta favorable de $44 \%{ }^{83}$. Para anidulafungina los datos publicados recientes son en uso combinado con voriconazol (ver más adelante); no hay estudios publicados de uso como monoterapia en AI.

La recomendación es usar caspofungina o micafungina como terapia alternativa en caso de aspergilosis refractaria o intolerantes a terapia con voriconazol, pero en ningún caso usarlas como antifúngico único en terapia primaria ${ }^{4}$. 
Figura 3. Algoritmo de evaluación de pacientes en riesgo de aspergilosis invasora con monitorización de galactomanano (GM) e imágenes de TAC de tórax. Según resultados se avanza en el proceso diagnóstico incluyendo realización de lavado bronco-alveolar (LBA) que descarta o confirma el diagnóstico según categoría EORTC/MSG con lo que se define la conducta terapéutica.

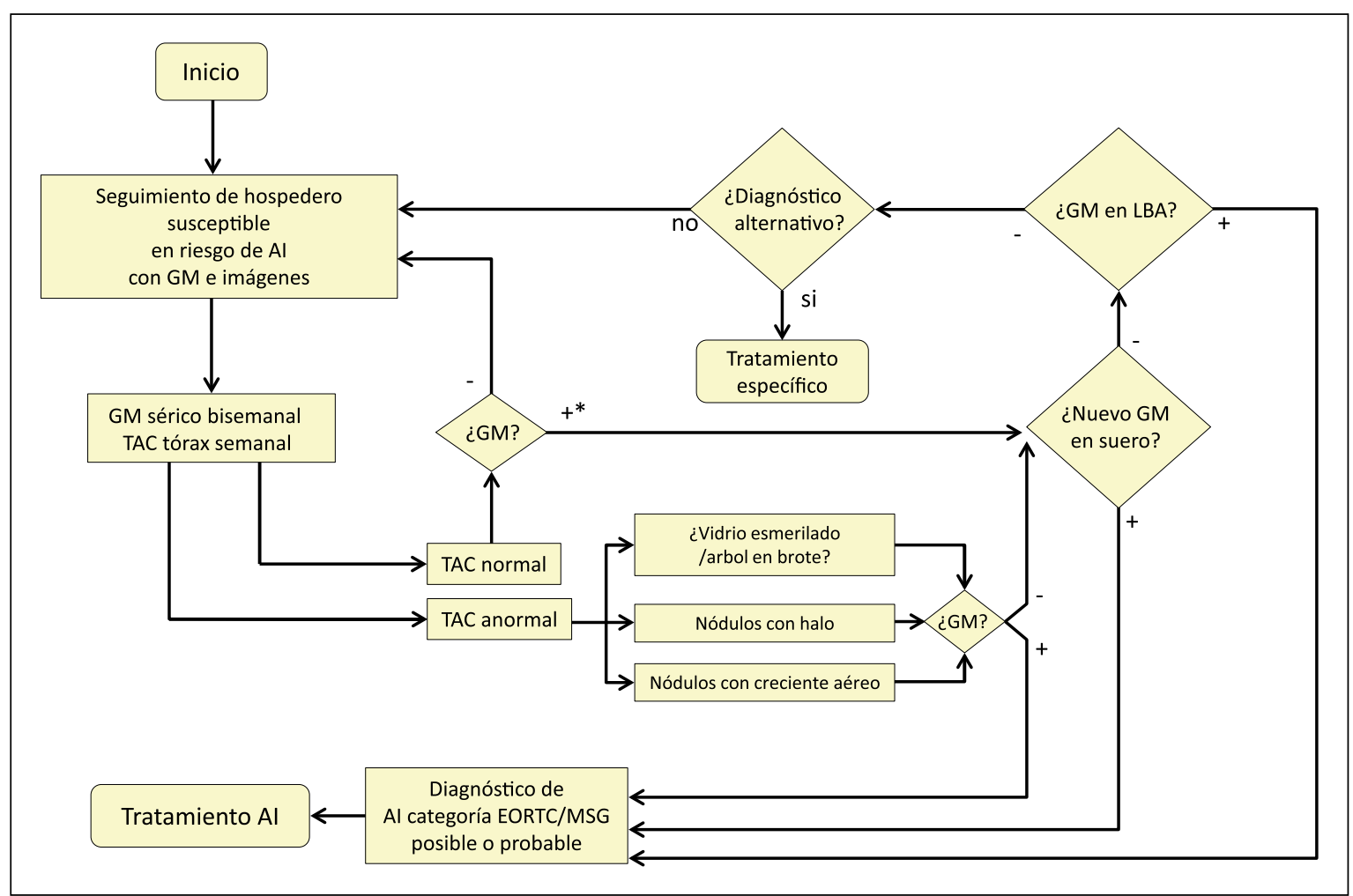

\section{Estrategias para la prescripción de antifúngicos}

Los antifúngicos se pueden utilizar como objetivo de una profilaxis o con fines terapéuticos según sea la certeza diagnóstica.

\section{Profilaxis primaria}

Como se enunciaba más arriba existe evidencia a favor del uso de posaconazol para disminuir EFI en pacientes mayores de 13 años con LMA o síndrome mielodisplásico con neutropenia post quimioterapia ${ }^{71}$, así como pacientes con enfermedad de injerto contra hospedero tipo II a IV ${ }^{72}$. Cornely demostró menor frecuencia de AI en pacientes neutropénicos en profilaxis con posaconazol vs fluconazol/itraconazol ( 1 vs $7 \%$ ) y menor mortalidad con diferencia estadísticamente significativa ${ }^{71}$.

Esta estrategia debe considerarse en pacientes de alto riesgo como neutropenia en LMA y también se debe incluir en los protocolos de manejo de prevención de EFI en trasplante pulmonar. La profilaxis de AI puede ser realizada de preferencia con posaconazol en vista de la mejor evidencia disponible; como alternativas considerar voriconazol y micafungina y, con menor grado de evidencia, se podría utilizar anfotericina inhalada.

La decisión de iniciar profilaxis antifúngica debe considerar la frecuencia de AI y los costos asociados. Su incorporación debe incluir un plan de evaluación ante sospecha de EFI y plan de terapia antifúngica para las infecciones fúngicas emergentes que puedan presentarse a pesar del uso de profilaxis junto a una estrategia de vigilancia de desarrollo de resistencia a azoles.

\section{Profilaxis secundaria}

Corresponde a la indicación de antifúngicos luego de que se ha completado el tratamiento de la EFI, ante el riesgo de reactivación durante la neutropenia post quimioterapia o trasplante. El beneficio esperable fue adecuadamente evidenciado en el trabajo de Cordonier y cols., quienes en un estudio prospectivo de uso de voriconazol hasta por 150 días como profilaxis secundaria en 45 receptores de TPH alogeneico con EFI previa, diagnosticaron tres episodios de EFI durante el seguimiento hasta un año, ninguno de ellos $\mathrm{AI}^{84}$.

La incorporación de profilaxis secundaria debe tener en cuenta lo señalado en el punto previo en cuanto a enfrentamiento diagnóstico de potenciales casos de EFI emergente, resistencia, costos y toxicidad.

\section{Uso terapéutico}

Definiciones. La prescripción por fiebre persistente en un paciente en riesgo de AI es conocida como terapia 
empírica. Si se indica un antifúngico en base a un diagnóstico presuntivo según resultados de marcadores/imágenes compatibles, se le denomina terapia precoz (del inglés pre-emptive). Finalmente, si la infección fúngica ha sido demostrada se habla de terapia dirigida.

\section{Terapia empírica}

Los estudios de Walsh y cols., en NF demostraron que anfotericina liposomal ${ }^{85} \mathrm{y}$ caspofungina ${ }^{86}$ lograban mejores resultados en una estrategia empírica de uso de antifúngicos en pacientes neutropénicos que persistían febriles, medidos a través de una evaluación compuesta que incluía resolución de la fiebre, ausencia de emergencia de infecciones fúngicas, efectividad sobre infecciones fúngicas presentes al inicio, falta de suspensión prematura por toxicidad y sobrevida a los 7 días. Curiosamente, en el mismo diseño de estudio, voriconazol no logró mejores resultados que anfotericina liposomal ${ }^{87}$ a pesar de ser conocida su efectividad en AI.

Por lo tanto, existe evidencia de beneficio con el uso de antifúngicos en escenarios de riesgo de AI, pero implica la administración de antifúngicos a pacientes con y sin EFI, agregando costos y riesgos de toxicidad. Adicionalmente, se debe señalar que luego de iniciar terapia antifúngica empírica, los plazos de duración de la terapia son difíciles de establecer, así como tampoco se puede definir la necesidad de profilaxis secundaria en eventos sucesivos de riesgo.

Esta estrategia es posible de plantear para pacientes de alto riesgo de $\mathrm{AI}$ en centros en que no es posible realizar vigilancia con biomarcadores e imágenes.

\section{Terapia precoz (del inglés pre-emptive)}

Esta estrategia considera el inicio de antifúngicos en la medida que se evidencian elementos diagnósticos de AI, lo que implica la vigilancia de los pacientes con biomarcadores, aislados o en combinación, como GM, BDG y/o RPC de Aspergillus bisemanal y realización de al menos TC de tórax una vez a la semana durante el período de riesgo de AI para la búsqueda activa de evidencias de EFI. En consideración de la mayor experiencia con GM y su mayor disponibilidad, es recomendable implementar la estrategia precoz con este marcador. Es de utilidad contar con un algoritmo decisional que plantee los pasos a seguir en las distintas posibilidades de combinación de resultados de marcadores e imágenes, que incluya el LBA para avanzar en el diagnóstico en casos de imágenes sospechosas y marcadores no concluyentes (Figura 3). En caso de resultados que sugieran $\mathrm{AI}$, la primera elección de antifúngico es voriconazol.

Uno de los mayores estudios que ha evidenciado el beneficio de esta estrategia se realizó en pacientes con cánceres hematológicos y documentó que se logra diagnosticar más casos de EFI e iniciar menos tratamientos antifúngicos empíricos, sin aumentar la mortalidad de los pacientes ${ }^{88}$. Esta estrategia no es adecuada para aquellos pacientes que reciben profilaxis antifúngica con actividad contra filamentosos ya que disminuyen la sensibilidad de los biomarcadores ${ }^{89}$.

\section{Terapia dirigida}

Se refiere al uso de la terapia más adecuada a la infección documentada. En caso de AI, voriconazol es el antifúngico de primera elección. En caso de no ser posible su administración, anfotericina en formulación lipídica es la alternativa adecuada.

En la Tabla 5 se resumen los antifúngicos recomendados, sus dosificaciones y vías de administración.

Asociaciones de antifúngicos en AI. Un estudio reciente comparó el uso de voriconazol más anidulafungina vs voriconazol en monoterapia, observando menor mortalidad a la semana 6 con la asociación, pero sin alcanzar diferencia estadísticamente significativa (19,3 vs 27,5\%). Sin embargo, en el subgrupo de pacientes con GM entre 1 y 1,5 , sí se logró determinar una significativa menor mortalidad al usar ambos antifúngicos $(15,7 \text { vs } 27,3 \%)^{90}$. En base a estos resultados, si bien no se puede generalizar que la terapia asociada para el manejo de AI garantice los mejores resultados, es posible considerar su uso en casos seleccionados.

En la Tabla 6, se presenta un resumen comparativo de las recomendaciones de uso de antifúngicos en las diferentes estrategias según las guías internacionales más recientemente publicadas ${ }^{4-6}$.

\section{Evaluación de la respuesta a terapia antifúngica con biomarcadores}

La monitorización de GM se correlaciona con la evolución y el pronóstico de la infección, tanto en pacientes neutropénicos como no neutropénicos. La disminución de GM sérico basal luego de una semana de tratamiento se asocia a mejor pronóstico ${ }^{91}$, no hay datos categóricos de seguimiento de GM en LBA y su correlación con pronóstico. No hay datos aún que demuestren la utilidad de BDG en el seguimiento de la terapia de $\mathrm{AI}^{4}$.

\section{Duración de la terapia antifúngica}

En los estudios publicados no se ha definido adecuadamente cuál es el período óptimo de tratamiento; sin embargo, en las guías internacionales se recomienda considerar terapia antifúngica por al menos 6 a 12 semanas $^{4}$.

Tal como se señalaba previamente, se debe considerar mantener la terapia antifúngica como profilaxis secundaria si la inmunosupresión se mantiene o incrementa. 


\begin{tabular}{|c|c|c|c|c|c|c|}
\hline & \multicolumn{2}{|c|}{ IDSA $^{4}$} & \multicolumn{2}{|c|}{$\mathrm{ECIL}^{5}$} & \multicolumn{2}{|c|}{ ESCMID-ECMM-ERS ${ }^{6}$} \\
\hline & Primaria & Alternativa & Primaria & Alternativa & Primaria & Alternativa \\
\hline Profilaxis & Posaconazol & $\begin{array}{c}\text { Voriconazol } \\
\text { Anfotericina inhalada* }\end{array}$ & ** & ** & Posaconazol & $\begin{array}{c}\text { Voriconazol } \\
\text { Anfotericina inhalada }\end{array}$ \\
\hline Empírico & ** & ** & ** & ** & Caspofungina & $\begin{array}{c}\text { Anfotericina liposomal } \\
\text { Voriconazol } \\
\text { Micafungina }\end{array}$ \\
\hline Precoz & $* *$ & ** & ** & ** & $\begin{array}{l}\text { Voriconazol } \\
\text { Isavuconazol }\end{array}$ & Anfotericina liposomal \\
\hline Dirigido & Voriconazol & $\begin{array}{c}\text { Anfotericina liposomal } \\
\text { Isavuconazol }\end{array}$ & $\begin{array}{l}\text { Voriconazol } \\
\text { Isavuconazol }\end{array}$ & Anfotericina liposomal & $\begin{array}{l}\text { Voriconazol } \\
\text { Isavuconazol }\end{array}$ & Anfotericina liposomal \\
\hline
\end{tabular}

\section{Indicaciones de tratamiento quirúrgico y procedimientos especiales}

Se debe complementar el tratamiento antifúngico con cirugía en caso de AI pulmonar con lesiones cercanas a grandes vasos o pericardio, lesiones que generan hemoptisis, erosión de pleura y endocarditis. En caso de endocarditis la cirugía debe ser precoz. Se puede considerar cirugía en AI que afecta al SNC, en sinusitis, osteomielitis y compromiso cutáneo. También se puede plantear en ausencia de respuesta a antifúngicos o resección quirúrgica de un nódulo único, previo a TPH o a quimioterapia intensiva a fin de disminuir la carga fúngica y eventual diseminación ${ }^{4}$.

En el caso de compromiso ocular, se requiere evaluación por oftalmólogo. En endoftalmitis, junto a la terapia sistémica con voriconazol, es posible administrar voriconazol o anfotericina desoxicolato intravitreo; en cambio, en queratitis se recomienda terapia tópica con voriconazol $^{4,92}$.

\section{Uso de factores estimulantes de colonias y disminución de nivel de inmunosupresión}

En la medida que sea posible se debe plantear acortar el período de neutropenia ya sea con uso de factores estimulantes de colonias o transfusiones de granulocitos ${ }^{4}$, y en usuarios de inmunosupresores, bajar sus dosis a la menor dosis posible que evite el rechazo del órgano trasplantado pero que mejore la reactividad del individuo evitando que la inmunosupresión perpetúe y agrave la AI.

\section{Aspergilosis emergente en pacientes bajo profilaxis con azoles}

En pacientes en que se sospecha o confirma AI estando bajo profilaxis con azoles, se debe preferir terapia con anfotericina liposomal; en caso que no sea posible su administración se puede tratar con equinocandinas ${ }^{4}$.

Es recomendable chequear las concentraciones plasmáticas del azol profiláctico; en caso de estar bajo la concentración considerada útil como profiláctica, es planteable utilizar el mismo azol ajustando la dosis; en estos casos, si se obtiene desarrollo de Aspergillus spp en las muestras clínicas, deberá evaluarse su susceptibilidad in vitro a antifúngicos.

\section{Aspergilosis invasora refractaria}

Previo a categorizar un episodio de infección refractaria, es importante confirmar el diagnóstico, descartar co-infecciones bacterianas o fúngicas, constatar concentraciones plasmáticas óptimas de antifúngicos (según disponiblidad) y optimizar la inmunidad; esto incluye resolver la neutropenia con uso de factores estimulantes de colonias o, en casos extremos, considerar la transfusión de granulocitos y disminuir la dosis de inmunosupresores. También se debe tener en cuenta que en el contexto de reconstitución inmune se observe un deterioro en las imágenes por lo que se debe evaluar esta posibilidad antes de catalogar falla de tratamiento ${ }^{93}$.

Luego de estas consideraciones, en caso de que se concluya que con mayor probabilidad se trate de una infección refractaria, la mejor opción es cambiar el antifúngico privilegiando cambiar por otra familia como polienos o equinocandinas en caso de uso de azoles iniciales o asociar antifúngicos incluyendo al menos un antifúngico nuevo.

\section{Desafíos futuros}

Si bien hay claros avances en el enfrentamiento de AI, aún hay diferentes tópicos en los que se requiere progresar, entre ellos un mejor conocimiento de su epidemiología 
en nuevos grupos de pacientes: receptores de anticuerpos monoclonales y biológicos, pacientes en estados críticos, EPOC avanzado, falla hepática, entre otros. El impacto de cambios climáticos, que incluyen elevación de temperatura, mayor frecuencia de desastres naturales, inundaciones, tsunamis, contaminación e inundaciones, en la medida que se incrementen en el futuro, podría generar un incremento de infecciones incluyendo aspergilosis en diferentes escenarios y tipos de pacientes ${ }^{94}$.

Otro aspecto que requiere particular atención en el momento actual y su desarrollo en el tiempo es la emergencia de resistencia a azoles en Aspergillus spp. De manera reciente se ha comunicado cifras tan elevadas como hasta $26 \%$ de $A$. fumigatus resistente de los aislados en algunos centros de países europeos ${ }^{95}$. Los motivos de este incremento de resistencia son probablemente multifactoriales, incluyendo el mayor uso de azoles en humanos como profilaxis o terapia, así como también en la industria agro-alimentaria. Se trata de un aspecto en evolución, con mecanismos moleculares identificados en el gen cyp $51 \mathrm{~A}$ para el cual existe poca información en Latinoamérica y para el que no contamos con datos en Chile.

Indudablemente las mejores estrategias diagnóstica, la incorporación de nuevos exámenes como la detección de compuestos orgánicos volátiles en aire espirado ${ }^{96}$ o biomarcadores en orina ${ }^{97}$ y su combinación con los métodos actuales, serán muy esperados en el futuro cercano, así como los resultados en estudios clínicos de nuevos antifúngicos en desarrollo ${ }^{98}$ que deberían aportar con mayor efectividad al manejo de AI.

\section{Conclusiones}

Aspergilosis es la EFI más frecuente en los pacientes inmunocomprometidos. Si bien hay importantes avances en el diagnóstico basado en la mejor caracterización de factores de riesgo, el uso de marcadores serológicos y la mejor interpretación de las imágenes, aún hay espacio para optimizar el diagnóstico en las fases precoces de la infección. Para esto resultan prometedores la incorporación de los factores de riesgo basados en la susceptibilidad genética del hospedero, la optimización de los nuevos métodos diagnósticos como la biología molecular y la incorporación en el futuro cercano de la medición de los productos orgánicos volátiles producidos por Aspergillus spp. Aún es de esperar mayor impacto con estrategias terapéuticas diseñadas de manera especial para grupos de pacientes específicos, incluyendo aquellos con factores de riesgo clásicos por su inmunosupresión, como aquellos aparentemente inmunocompetentes que nos plantean nuevos desafíos. La mayor capacidad diagnóstica y la disponibilidad de las nuevas terapias antifúngicas deberían seguir contribuyendo a mejorar el pronóstico de esta infección; sin embargo, la emergencia de la creciente resistencia a azoles podría disminuir el optimismo frente a este esperado mejor pronóstico.

Agradecimientos. A la Red Nacional de Micología Médica, fundada en 2011, que ha motivado este trabajo de revisión, la constante puesta al día en la generación de información epidemiológica nacional y la elaboración de recomendaciones actualizadas de manejo de infecciones fúngicas. A Mabel Aylwin, Teresa Bidart y María Elena Santolaya por su valiosa colaboración en la revisión del manuscrito.

\section{Resumen}

La enfermedad fúngica invasora producida por Aspergillus spp., es la infección por hongos filamentosos más frecuentemente reportada en individuos inmunocomprometidos y responsable de una muy alta mortalidad en este grupo de pacientes. En los últimos años se han logrado importantes avances, tanto en su diagnóstico como terapéuticos. Al momento actual se ha identificado una serie de factores de riesgo asociados a su desarrollo, permitiendo la categorización de pacientes en condición de alto, intermedio y bajo riesgo de aspergilosis invasora (AI); y también se han establecido criterios diagnósticos que consideran factores del hospedero, laboratorio micológico tradicional, biomarcadores como galactomanano y $1 \rightarrow 3-\beta$-d-glucano, junto a la mejor comprensión e interpretación de las imágenes tomográficas que han permitido consensuar las categorías diagnósticas. Esto, sumado a la incorporación de nuevos antifúngicos y estrategias terapéuticas en diferentes escenarios, ha permitido lograr una disminución de la mortalidad asociada. En este artículo se realiza una puesta al día de los aspectos epidemiológicos, los factores de riesgo, el diagnóstico, la prevención y profilaxis además del enfrentamiento terapéutico, incluyendo las estrategias de uso de terapia antifúngica empírica, precoz y dirigida, así como los aspectos más relevantes de los antifúngicos de primera elección y alternativos para el manejo actualizado de AI.

\section{Referencias bibliográficas}

1.- Dagenais T R, Keller N P. Pathogenesis of Aspergillus fumigatus in invasive aspergillosis. Clin Microb Rev 2009; 22: 447-65 doi: 10.1128/CMR.00055-08.

2.- Latgé J P. Aspergillus fumigatus and aspergillosis. Clin. Microbiol. Rev. 1999, 12: 310-50.

3.- Fortún J, Meije Y, Fresco G, Moreno S. Aspergillosis. Clinical forms and treatment. Enferm Infecc Microbiol Clin. 2012; 30: 201-8. doi: 10.1016/j.eimc.2011.12.005.

4.- Patterson T F, Thompson G R 3rd, Denning
D W, Fishman J A, Hadley S, Herbrecht R, et al. Practice guidelines for the diagnosis and management of aspergillosis: 2016 Update by the Infectious Diseases Society of America. Clin Infect Dis 2016 Jun 29. pii: ciw326 doi: 10.1093/cid/ciw326.

5.- Tissot F, Agrawal S, Pagano L, Petrikkos G, 
Groll A H, Skiada A, et al. ECIL-6 guidelines for the treatment of invasive candidiasis, aspergillosis and mucormycosis in leukemia and hematopoietic stem cell transplant patients. Haematologica 2017; 102: 433-44 doi:10.3324/ haematol.2016.152900.

6.- Ullmann A J, Aguado J M, Arikan-Akdagli S, Denning D W, Groll A H, Lagrou K, et al. Diagnosis and management of aspergillus diseases: executive summary of the 2017 ESCMID-ECMM-ERS guideline. Clin Microbiol Infect 2018; 24: e1-e38. doi: 10.1016/j.cmi.2018.01.002.

7.- Girmenia C, Ferretti A, Barberi W. Epidemiology and risk factors for invasive fungal diseases in hematopoietic stem cell transplantation. Curr Opin Hematol 2014; 21: 459-65. doi: 10.1097/ MOH.0000000000000086.

8.- Taccone F S, Van den Abeele A M, Bulpa P, Misset B, Meersseman W, Cardoso T, et al. Epidemiology of invasive aspergillosis in critically ill patients: clinical presentation, underlying conditions, and outcomes. Crit Care. 2015; 19:7. doi: 10.1186/s13054-014-0722-7.

9.- Caira M, Girmenia C, Fadda R M, Mitra M E, Picardi M, Van Lint M T, et al. Invasive fungal infections in patients with acute myeloid leukemia and in those submitted to allogeneic hemopoietic stem cell transplant: who is at highest risk? Eur J Haematol 2008; 81: 242-3 doi: 10.3390/ijms13010774.

10.- Nucci M, Anaissie E. How we treat invasive fungal diseases in patients with acute leukemia: the importance of an individualized approach. Blood 2014; 124: 3858-69 doi: 10.1182/ blood-2014-04-516211.

11.- Rabagliati R, Fuentes G, Guzmán A M, Orellana E, Oporto J, Aedo I, et al. Enfermedad fúngica invasora en pacientes hematooncológicos y receptores de trasplante de precursores hematopoyéticos bajo la perspectiva de los criterios diagnósticos EORTC/MSG. Rev Chilena Infectol 2009; 26: 212-9. http://dx.doi.org/10.4067/S071610182009000400002 .

12.- Cruz Ch R, Piontelli E. Enfermedad fúngica invasora en la Región de Valparaíso, Chile 2004 a 2009. Rev Chilena Infectol 2011; 28: 123-9. http://dx.doi.org/10.4067/S071610182011000200004

13.- Rabagliati R, Bertín P, Cerón I, Rojas H, Domínguez I, Vera A, et al. Epidemiología de neutropenia febril en pacientes adultos con leucemia aguda y linfoma en quimioterapia. Estudio de cohorte de hospitales público y privado de Santiago, Chile. Rev Chilena Infectol 2014; 31: 721-8. http://dx.doi. org/10.4067/S0716-10182014000600013.

14.- Nucci M, Anaissie E. Infections in patients with multiple myeloma in the era of high-dose therapy and novel agents. Clin Infect Dis 2009;
49: 1211-25. doi: 10.1086/605664.

15.- Pagano L, Caira M, Candoni A, Offidani M, Fianchi L, Martino B, et al. The epidemiology of fungal infections in patients with hematologic malignancies: the SEIFEM-2004 study. Haematologica 2006; 91: 1068-75. PMID: 16885047.

16.- Singh N, Paterson D L. Aspergillus infections in transplant recipients. Clin Microbiol Rev 2005; 18: 44-69. DOI:10.1128/CMR.18.1.4469.2005.

17.- Ben-Ami R, Lewis R E, Kontoyiannis D P. Invasive mould infections in the setting of hematopoietic cell transplantation: current trends and new challenges. Curr Opin Infect Dis 2009; 22: 376-84. doi: 10.1097/ QCO.0b013e32832db9f3.

18.- Marr K A, Carter R A, Crippa F, Wald A, Corey L. Epidemiology and outcome of mould infections in hematopoietic stem cell transplant recipients. Clin Infect Dis 2002; 34: 909-17 DOI:10.1086/339202.

19.- Marr K A, Carter R A, Boeckh M, Martin $\mathrm{P}$, Corey L. Invasive aspergillosis in allogeneic stem cell transplant recipients: changes in epidemiology and risk factors. Blood 2002; 100: 4358-66. DOI 10.1182/ blood-2002-05-1496.

20.- Pagano L, Caira M, Nosari A, Van Lint M T, Candoni A, Offidani M, et al. Fungal infections in recipients of hematopoietic stem cell transplants: results of the SEIFEM B-2004 study-Sorveglianza Epidemiologica Infezioni Fungine Nelle Emopatie Maligne. Clin Infect Dis 2007; 45: 1161-70. DOI: $10.1086 / 522189$.

21.- Neofytos D, Hom D, Anaissie E, Steinbach W, Olyaei A, Fishman J, et al. Epidemiology and outcome of invasive fungal infection in adult hematopoietic stem cell transplant recipients: analysis of Multicenter Prospective Antifungal Therapy (PATH) Alliance registry. Clin Infect Dis 2009; 48: 265-73 doi: 10.1086/595846.

22.- Valdez J M, Scheinberg P, Nunez O, Wu C O, Young N S, Walsh T J. Decreased infectionrelated mortality and improved survival in severe aplastic anemia in the past two decades. Clin Infect Dis 2011; 52: 726-35 doi: 10.1093/ $\mathrm{cid} / \mathrm{ciq} 245$.

23.- Torres H A, Bodey G P, Rolston K V, Kantarjian H M, Raad I I, Kontoyiannis D P. Infections in patients with aplastic anemia: experience at a tertiary care cancer center. Cancer 2003; 98: 86-93. DOI: 10.1002/ cncr.11478.

24.- Neofytos D, Fishman J A, Hom D, Anaissie E, Chang C H, Olyaei A, Pfaller M W, et al. Epidemiology and outcome of invasive fungal infections in solid organ transplant recipients. Transpl Infect Dis 2010; 12: 220-9 doi: 10.1111/j.1399-3062.2010.00492.x

25.- García-Ruiz J C, Amutio E, Ponton J. Invasive fungal infection in immunocompromised patients. Rev Iberoam Micol 2004; 21: 55-62. PMID: 15538828.

26.- Cornet M, Fleury L, Maslo C, Bernard J F, Brücker G, Invasive Aspergillosis Surveillance Network of the Assistance Publique-Hôpitaux de Paris. Epidemiology of invasive aspergillosis in France: a six-year multicentric survey in the Greater Paris area. J Hosp Infect. 2002; 51: 288-96 doi: 10.3324/haematol.2011.044636.

27.- Holding K J, Dworkin M S, Wan P C, Hanson D L, Klevens R M, Jones J L, et al. Aspergillosis among people infected with human immunodeficiency virus: incidence and survival. Adult and adolescent spectrum of HIV disease project. Clin Infect Dis 2000; 31: 12537. DOI: $10.1086 / 317452$.

28.- Wallis R S, Broder M S, Wong J Y, Hanson M E, Beenhouwer D O. Granulomatous infectious diseases associated with tumor necrosis factor antagonists. Clin Infect Dis 2004; 38: 1261-5. DOI: $10.1086 / 383317$.

29.- Meersseman W, Lagrou K, Maertens J, Van Wijngaerden E. Invasive aspergillosis in the Intensive Care Unit. Clin Infect Dis 2007; 45: 205-16. DOI: 10.1086/518852.

30.- Guinea J, Torres-Narbona M, Gijón P, Muñoz P, Pozo F, Peláez T, et al. Pulmonary aspergillosis in patients with chronic obstructive pulmonary disease: incidence, risk factors, and outcome. Clin Microbiol Infect 2010; 16: 870-7 doi: 10.1111/j.1469-0691.2009.03015.x.

31.- Montagna M T, Caggiano G, Lovero G, De Giglio O, Coretti C, Cuna T, et al. Epidemiology of invasive fungal infections in the intensive care unit: results of a multicenter Italian survey (AURORA Project) Infection 2014; 42: 141-51 doi: 10.1007/s15010-0130432-0.

32.- Rambaldi B, Russo D, Pagano L. Defining invasive fungal infection risk in hematological malignancies: a new tool for clinical practice. Mediterr J Hematol Infect Dis 2017; 9: e2017012. doi: 10.4084/MJHID.2017.012.

33.- Baddley J W. Clinical risk factors for invasive aspergillosis. Med Mycol 2011; 49 Suppl 1: S7-S12. doi: 10.3109/13693786.2010.505204.

34.- Vonberg R P, Gastmeier P. Nosocomial aspergillosis in outbreak settings. J Hosp Infect. 2006; 63: 246-54. DOI: 10.1016/j. jhin.2006.02.014.

35.- Cunha C, Rodrigues F, Zelante T, Aversa F, Romani L, Carvalho A. Genetic susceptibility to aspergillosis in allogeneic stem-cell transplantation. Med Mycol. 2011; 49 Suppl 1: S137-43. DOI: 10.3109/13693786.2010.508797.

36.- Schwartz S, Thiel E. Clinical presentation of invasive aspergillosis. Mycoses. 1997; 40 Suppl 2: 21-4.

37.- Zmelli O Z, Soubani A O. Pulmonary aspergillosis: a clinical update. Q J Med 2007; 100: 317-34. DOI: 10.1093/qjmed/hcm035. 
38.- Paterson DL. New clinical presentations of invasive aspergillosis in non-conventional hosts. Clin Microbiol Infect 2004; 10 (Suppl. 1): 24-30 https://doi.org/10.1111/j.14709465.2004.00840.x

39.- Kousha M, Tadi R, Soubani AO. Pulmonary aspergillosis: a clinical review. Eur Respir Rev 2011; 20: 156-74. doi: 10.1183/09059180.00001011.

40.- Soubani A O, Chandrasekar P H. The clinical spectrum of pulmonary aspergillosis. Chest 2002; 121: 1988-99. PMID: 12065367.

41.- Ascioglu S, Rex J H, De Pauw B, Bennett J E, Billc J, Crokaert F, et al. Defining opportunistic invasive fungal infections in immunocompromised patients with cancer and hematopoietic stem cell transplants: An International Consensus. Clin Infect Dis 2002; 34: 7-14. DOI: 10.1086/323335.

42.- De Pauw B, Walsh T J, Donnelly P, Stevens D A, Edwards J E, Calandra T, et al. Revised definitions of invasive fungal disease from the European Organization for Research and Treatment of Cancer/Invasive Fungal Infections Cooperative Group and the National Institute of Allergy and Infectious Diseases Mycoses Study Group (EORTC/MSG) Consensus Group. Clin Infect Dis 2008; 46: 1813-21. doi: $10.1086 / 588660$

43.- Cruz R. Guía para el diagnóstico de laboratorio de enfermedad fúngica invasora por hongos filamentosos. Rev Chilena Infectol 2014; 31: 173-9 http://dx.doi.org/10.4067/S071610182014000200008.

44.- Sulahian A, Porcher R, Bergeron A, Touratier S, Raffoux E, Menotti J, et al. Use and limits of (1-3)- $\beta$-d-glucan assay (Fungitell), compared to galactomannan determination (Platelia Aspergillus), for diagnosis of invasive aspergillosis. J Clin Microbiol. 2014; 52: 232833 doi: 10.1128/JCM.03567-13.

45.- Maertens J, Verhaegen J, Lagrou K, Van Eldere J, Boogaerts M. Screening for circulating galactomannan as a noninvasive diagnostic tool for invasive aspergillosis in prolongued neutropenic patients and stem cell transplantation recipients: a prospective validation. Blood 2001; 97: 1604-10.

46.- Chong G M, Maertens J A, Lagrou K, Driessen G J, Cornelissen J J, Rijnders B J. Diagnostic performance of galactomannan antigen testing in cerebrospinal fluid. J Clin Microbiol 2016; 54: 428-31. doi: 10.1128/JCM.02913-15.

47.- Leeflang M M, Debets-Ossenkopp Y J, Wang J, Visser C E, Scholten RJ, Hooft L, et al. Galactomannan detection for invasive aspergillosis in immunocompromised patients. Cochrane Database Syst Rev 2015; 12:CD007394. doi: 10.1002/14651858. CD007394.

48.- Marr K A, Balajee S A, McLaughlin L, Tabouret M, Bentsen C, Walsh T J. Detection of galactomannan antigenemia by enzyme immunoassay for the diagnosis of invasive aspergillosis: variables that affect performance. J Infect Dis 2004; 190: 641-9. DOI: $10.1086 / 422009$.

49.- Maertens J A, Klont R, Masson C, Theunissen K, Meersseman W, Lagrou K, et al. Optimization of the cutoff value for the Aspergillus double-sandwich enzyme immunoassay. Clin Infect Dis 2007; 44: 132936. DOI: $10.1086 / 514349$.

50.- Ku N S, Han S H, Choi J Y, Kim S B, Kim H W, Jeong S J. Diagnostic value of the serum galactomannan assay for invasive aspergillosis: it is less useful in non-haematological patients. Scand J Infect Dis 2012; 44: 600-4 doi: 10.3109/00365548.2012.657672.

51.- Kwak E J, Husain S, Obman A, Meinke L, Stout J, Kusne S, et al. Efficacy of galactomannan antigen in the Platelia Aspergillus enzyme immunoassay for diagnosis of invasive aspergillosis in liver transplant recipients. J Clin Microbiol 2004; 42: 435-8 doi: 10.1128/JCM.42.1.435-438.2004.

52.- Maertens J, Maertens V, Theunissen K, Meersseman W, Meersseman P, Meers S, et al. Bronchoalveolar lavage fluid galactomannan for the diagnosis of invasive pulmonary aspergillosis in patients with hematologic diseases. Clin Infect Dis 2009; 49: 1688-93. doi: 10.1086/647935.

53.- Held J, Schmidt T, Thornton CR, Kotter E, Bertz H. Comparison of a novel Aspergillus lateral-flow device and the Platelia ${ }^{\circledR}$ galactomannan assay for the diagnosis of invasive aspergillosis following haematopoietic stem cell transplantation. Infection 2013; 41 : 1163-9 doi: 10.1007/s15010-013-0472-5.

54.- White P L, Wingard J R, Bretagne S, Löffler J, Patterson T F, Slavin M A, et al. Aspergillus polymerase chain reaction: systematic review of evidence for clinical use in comparison with antigen testing. Clin Infect Dis 2015; 61: 1293 303 doi: 10.1093/cid/civ507.

55.- Aguado J M, Vázquez L, Fernández-Ruiz M, Villaescusa T, Ruiz-Camps I, Barba P, et al. Serum galactomannan versus a combination of galactomannan and polymerase chain reactionbased Aspergillus DNA detection for early therapy of invasive aspergillosis in high-risk hematological patients: a randomized controlled trial. Clin Infect Dis 2015; 60: 405-14. doi: $10.1093 / \mathrm{cid} / \mathrm{ciu} 833$.

56.- Caillot D, Couaillier J F, Bernard A, Casasnovas O, Denning D W, Mannone L, et al. Increasing volume and changing characteristics of invasive pulmonary aspergillosis on sequential thoracic computed tomography scans in patients with neutropenia. J Clin Oncol 2001; 19: 253-9. DOI: 10.1200/JCO.2001.19.1.253.

57.- Georgiadou S P, Sipsas N V, Marom E M, Kontoyiannis D P. The diagnostic value of halo and reversed halo signs for invasive mold infections in compromised hosts. Clin Infect Dis 2011 ; 52: 1144-55. doi: 10.1093/cid/cir122.

58.- Nucci M, Nouér SA, Cappone D, Anaissie E. Early diagnosis of invasive pulmonary aspergillosis in hematologic patients: an opportunity to improve the outcome. Haematologica 2013; 98 (11): 1657-60. doi: 10.3324/haematol.2013.094359.

59.- Henzler C, Henzler T, Buchheidt D, Nance JW, Weis CA, Vogelmann R, et al. Diagnostic performance of contrast enhanced pulmonary computed tomography angiography for the detection of angioinvasive pulmonary aspergillosis in immunocompromised patients. Sci Rep 2017 30; 7(1): 4483-6 doi: 10.1038/ s41598-017-04470-6.

60.- Hot A, Maunoury C, Poiree S, Lanternier F, Viard J P, Loulergue P, et al. Diagnostic contribution of positron emission tomography with $\left[{ }^{18} \mathrm{~F}\right]$ fluorodeoxyglucose for invasive fungal infections. Clin Microbiol Infect 2011; 17 (3): 409-17 doi: 10.1111/j.14690691.2010.03301.x.

61.- Rhame F S, Streifel A J, Kersey J H Jr, McGlave P B. Extrinsic risk factors for pneumonia in the patient at high risk of infection. Am J Med 1984; 76: 42-52.

62.- Sherertz R J, Belani A, Kramer B S, Elfenbein G J, Weiner R S, Sullivan M L, et al. Impact of air filtration on nosocomial aspergillus infections. Unique risk of bone marrow transplant recipients. Am J Med 1987; 83: 70918.

63.- Oren I, Haddad N, Finkelstein R, Rowe J M. Invasive pulmonary aspergillosis in neutropenic patients during hospital construction: before and after chemoprophylaxis and institution of HEPA filters. Am J Hematol 2001; 66: 257-62. DOI:10.1002/ajh.1054.

64.- Walsh T J, Dixon D M. Nosocomial aspergillosis: environmental microbiology, hospital epidemiology, diagnosis and treatment. Eur J Epidemiol 1989; 5: 131-42.

65.- Carter C D, Barr B A. Infection control issues in construction and renovation. Infect Control Hosp Epidemiol 1997; 18: 587-96.

66.- Sehulster L, Chinn R Y; CDC; HICPAC. Guidelines for environmental infection control in health-care facilities. Recommendations of CDC and the Healthcare Infection Control Practices Advisory Committee (HICPAC). MMWR Recomm Rep 2003; 52 (RR-10): 1-42.

67.- Cuenca-Estrella M. Antifungal agents in the treatment of systemic infections: Relevance of mechanism of action, activity profile and resistances. Rev Esp Quimioter 2010; 23: 16976.

68.- Herbrecht R, Denning D W, Patterson T F, Bennett J E, Greene R E, Oestmann J-W, et al. Voriconazole versus amphotericin B for primary therapy of invasive aspergillosis. $\mathrm{N}$ 
Engl J Med 2002; 347: 408-15. DOI: 10.1056/ NEJMoa020191.

69.- Wingard J R, Carter S L, Walsh T J, Kurtzberg J, Small T N, Baden L R, et al. Randomized, double-blind trial of fluconazole versus voriconazole for prevention of invasive fungal infection after allogeneic hematopoietic cell transplantation. Blood 2010; 116: 5111-8. doi: 10.1182/blood-2010-02-268151.

70.- Pascual A, Calandra T, Bolay S, Buclin T, Bille $\mathrm{J}$, Marchetti O. Voriconazole therapeutic drug monitoring in patients with invasive mycoses improves efficacy and safety outcomes. Clin Infect Dis 2008; 46: 201-11. doi: 10.1086/524669.

71.- Cornely O A, Maertens J, Winston D J, Perfect J, Ullmann A J, Walsh T J, et al. Posaconazole vs. fluconazole or itraconazole prophylaxis in patients with neutropenia. N Engl J Med 2007; 356: 348-59. DOI:10.1056/NEJMoa061094.

72.- Ullmann A J, Lipton J H, Vesole D H, Chandrasekar P, Langston A, Tarantolo S R, et al. Posaconazole or fluconazole for prophylaxis in severe graft-versus-host disease. N Engl J Med 2007; 356 (4): 335-47 DOI:10.1056/ NEJMoa061098.

73.- Walsh T J, Raad I, Patterson T F, Chandrasekar P, Donowitz G R, Graybill R, et al. Treatment of invasive aspergillosis with posaconazole in patients who are refractory to or intolerant of conventional therapy: an externally controlled trial. Clin Infect Dis 2007; 44: 2-12. DOI: 10.1086/508774.

74.- Maertens J A, Raad I I, Marr K A, Patterson T F, Kontoyiannis D P, Cornely O A, et al. Isavuconazole versus voriconazole for primary treatment of invasive mould disease caused by Aspergillus and other filamentous fungi (SECURE): a phase 3, randomised-controlled, non-inferiority trial. Lancet 2016; 387: 760-69 doi: 10.1016/S0140-6736(15)01159-9.

75.- Caillot D, Bassaris H, McGeer A, Arthur C, Prentice H G, Seifert W, et al. Intravenous itraconazole followed by oral itraconazole in the treatment of invasive pulmonary aspergillosis in patients with hematologic malignancies, chronic granulomatous disease, or AIDS. Clin Infect Dis 2001; 33: 83-90. DOI:10.1086/323020.

76.- Cordonnier C, Bresnik M, Ebrahimi R. Liposomal amphotericin B (AmBisome) efficacy in confirmed invasive aspergillosis and other filamentous fungal infections in immunocompromised hosts: a pooled analysis. Mycoses. 2007; 50: 205-9. DOI: 10.1111/j.1439-0507.2007.01362.x.

77.- Cornely O A, Maertens J, Bresnik M, Ebrahimi R, Ullmann A J, Bouza E, et al. Liposomal amphotericin B as initial therapy for invasive mold infection: a randomized trial comparing a high-loading dose regimen with standard dosing (AmBiLoad trial). Clin Infect Dis 2007;
44: 1289-97. DOI: 10.1086/514341.

78.- Cortés J A, Soto R, Álvarez C A, Buitrago G, Camargo R, Cataño J C, et al. Consenso de uso de antimicrobianos en pacientes críticamente enfermos con falla renal o en riesgo de padecerla. Infectio $2011 ; 15$ : 49-63.

79.- Monforte V, Ussetti P, Gavaldà J, Bravo C, Laporta R, Len O, et al. Feasibility, tolerability, and outcomes of nebulized liposomal amphotericin B for Aspergillus infection prevention in lung transplantation. J Heart Lung Transplant 2010; 29: 523-30. doi: 10.1016/j. healun.2009.11.603.

80.- Viscoli C, Herbrecht R, Akan H, et al. An EORTC phase II study of caspofungin as first-line therapy of invasive aspergillosis in haematological patients. J Antimicrob Chemother 2009; 64: 1274-81 doi: 10.1093/jac/ dkp355.

81.- Maertens J, Egerer G, Shin W S, Reichert D, Stek M, Chandwani S, et al. Caspofungin use in daily clinical practice for treatment of invasive aspergillosis: results of a prospective observational registry. BMC Infect Dis 2010; 10: 182. doi: 10.1186/1471-2334-10-182.

82.- van Burik J A, Ratanatharathorn V, Stepan D E, Miller C B, Lipton J H, Vesole D H, et al. Micafungin versus fluconazole for prophylaxis against invasive fungal infections during neutropenia in patients undergoing hematopoietic stem cell transplantation. Clin Infect Dis 2004; 39: 1407-16. DOI: 10.1086/422312.

83.- Denning D W, Marr K A, Lau W M, Facklam D P, Ratanatharathorn V, Becker C, et al. Micafungin (FK463), alone or in combination with other systemic antifungal agents, for the treatment of acute invasive aspergillosis. J Infect 2006; 53: 337e49. DOI:10.1016/j. jinf.2006.03.003.

84.- Cordonnier C, Rovira M, Maertens J, Olavarria E, Faucher C, Bilger K, et al. Voriconazole for secondary prophylaxis of invasive fungal infections in allogeneic stem cell transplant recipients: results of the VOSIFI study. Haematologica 2010; 95: 1762-8. doi: 10.3324/ haematol.2009.020073

85.- Walsh T J, Finberg R W, Arndt C, Hiemenz J, Schwartz C, Bodensteiner D, et al. Liposomal amphotericin B for empirical therapy in patients with persistent fever and neutropenia. National Institute of Allergy and Infectious Diseases Mycoses Study Group. N Engl J Med 1999; 340: 764-71.

86.- Walsh T J, Teppler H, Donowitz G R, Maertens J A, Baden L R, Dmoszynska A, et al. Caspofungin versus liposomal amphotericin $\mathrm{B}$ for empirical antifungal therapy in patients with persistent fever and neutropenia. N Engl J Med 2004; 351: 1391-402. DOI: 10.1056/ NEJMoa040446.

87.- Walsh T J, Pappas P, Winston D J, Lazarus H
M, Petersen F, Raffalli J, et al. Voriconazole compared with liposomal amphotericin B for empirical antifungal therapy in patients with neutropenia and persistent fever. N Engl J Med 2002; 346: 225-34. DOI:10.1056/ NEJM200201243460403.

88.- Cordonnier C, Pautas C, Maury S, Vekhoff A, Farhat H, Suárez F, et al. Empirical versus preemptive antifungal therapy for high-risk, febrile, neutropenic patients: a randomized, controlled trial. Clin Infect Dis 200; 48: 1042 51. doi: 10.1086/597395.

89.- Duarte RF, Sánchez-Ortega I, Cuesta I, Arnan M, Patiño B, Fernández de Sevilla A, Gudiol C, et al. Serum galactomannanbased early detection of invasive aspergillosis in hematology patients receiving effective antimold prophylaxis. Clin Infect Dis 2014; 59: 1696-702. doi: 10.1093/cid/ciu673.

90.- Marr K A, Schlamm H T, Herbrecht R, Rottinghaus S T, Bow E J, Cornely O A, et al. Combination antifungal therapy for invasive aspergillosis: a randomized trial. Ann Intern Med. 2015; 162: 81-9. doi: 10.7326/M13-2508.

91.- Park S H, Choi S M, Lee D G, Choi J H, Kim $\mathrm{S}$ H, Kwon J C, et al. Serum galactomannan strongly correlates with outcome of invasive aspergillosis in acute leukaemia patients. Mycoses. 2011; 54: 523-30 doi: 10.1111/j.14390507.2010.02009.x.

92.- Shen Y C, Wang C Y, Tsai H Y, Lee H N. Intracameral voriconazole injection in the treatment of fungal endophthalmitis resulting from keratitis. Am J Ophthalmol 2010; 149: 916-21. doi: 10.1016/j.ajo.2010.01.024.

93.- Nucci M, Perfect J R. When primary antifungal therapy fails. Clin Infect Dis 2008; 46: 142633. DOI: $10.1086 / 587101$.

94.- Mirsaeidi M, Motahari H, Taghizadeh Khamesi M, Sharifi A, Campos M, Schraufnagel D E. Climate change and respiratory infections. Annals ATS 2016; 13: 1223-30 https://doi. org/10.1513/AnnalsATS.201511-729PS.

95.- Chowdhary A, Sharma C, Meis J F. Azoleresistant aspergillosis: epidemiology, molecular mechanisms, and treatment. J Infect Dis 2017; 216 (suppl 3): S436-44 doi: 10.1093/infdis/ jix210.

96.- Koo S, Thomas H R, Daniels S D, Lynch R C, Fortier S M, Shea M M, et al. A breath fungal secondary metabolite signature to diagnose invasive aspergillosis. Clin Infect Dis 2014; 59: 1733-40 doi: 10.1093/cid/ciu725.

97.- Reischies F M, Raggam R B, Prattes J, Krause R, Eigl S, List A, et al. Urine galactomannanto-creatinine ratio for detection of invasive aspergillosis in patients with hematological malignancies. J Clin Microbiol 2016; 54: 771-4 doi: 10.1128/JCM.02969-15.

98.- Perfect J R. The antifungal pipeline: a reality check. Nat Rev Drug Discov 2017; 16: 603-16 doi: 10.1038/nrd.2017.46. 